\title{
Departments involved during the first episode of acute heart failure and analysis of emergency department revisits and rehospitalisations: an outlook through the NOVICA cohort
}

\author{
Òscar Miró ${ }^{1,2, *}$, Ana García Sarasola ${ }^{3,{ }^{*}}$, Carolina Fuenzalida ${ }^{1}$, Sofía Calderón ${ }^{1}$, Javier Jacob ${ }^{4}$, Alfons Aguirre ${ }^{5}$, \\ Da M. Wu ${ }^{1,6}$, Miguel A. Rizzi ${ }^{3}$, Pierre Malchair ${ }^{4}$, Antonio Haro ${ }^{4}$, Sergio Herrera ${ }^{2}$, Víctor Gil ${ }^{1}$, Francisco Javier \\ Martín-Sánchez ${ }^{7,8}$, Pere Llorens ${ }^{9}$, Pablo Herrero Puente ${ }^{10}$, Héctor Bueno ${ }^{8,11}$, Alberto Domínguez Rodríguez ${ }^{12}$, \\ Christian E. Müller ${ }^{2,13}$, Alexandre Mebazaa ${ }^{2,14}$, Ovidiu Chioncel $^{15}$, Aitor Alquézar ${ }^{3}$, on behalf of the ICA- \\ SEMES Research Group \\ ${ }^{1}$ Emergency Department, Hospital Clínic, Barcelona; “Emergencies: processes and pathologies” Research \\ Group, IDIBAPS, University of Barcelona, Barcelona, Catalonia, Spain. \\ ${ }^{2}$ The GREAT (Global REsearch in Acute cardiovascular conditions Team) network \\ ${ }^{3}$ Emergency Department, Hospital de la Santa Creu I Sant Pau, Barcelona, Catalonia, Spain \\ ${ }^{4}$ Emergency Department, Hospital Universitari de Bellvitge, L'Hospitalet de Llobregat, Barcelona, Catalonia, \\ Spain. \\ ${ }^{5}$ Emergency Department, Hospital del Mar, Barcelona, Catalonia, Spain. \\ ${ }^{6}$ San Juan Bautista School of Medicine, San Juan de Puerto Rico, Puerto Rico. \\ ${ }^{7}$ Emergency Department, Hospital Clínico San Carlos, Madrid, Instituto de Investigación Sanitaria San Carlos \\ (IdISSC), Universidad Complutense de Madrid, Spain. \\ ${ }^{8}$ Centro Nacional de Investigaciones Cardiovasculares (CNIC), Madrid, Spain \\ ${ }^{9}$ Emergency Department, Hospital Universitario Central de Asturias, Oviedo, Spain. \\ ${ }^{10}$ Emergency Department, Home Hospitalization and Short Stay Unit, Hospital General de Alicante, Alicante, \\ Spain. \\ ${ }^{11}$ Cardiology Department, Hospital 12 de Octubre, Universidad Complutense, Madrid, Spain \\ ${ }^{12}$ Cardiology Department, Hospital Universitario de Canarias, Tenerife, Spain \\ ${ }^{13}$ Cardiology Department, University Hospital of Basel, Basel, Switzerland. \\ ${ }^{14}$ Department of Anesthesiology and Critical Care Medicine, Saint Louis Lariboisière University Hospital, \\ Université Paris Diderot, Paris, France. \\ ${ }^{15}$ Emergency Institute for Cardiovascular Diseases, Prof. C. C. Iliescu, 1 University of Medicine Carol Davila, \\ Bucharest, Romania.
}

* Òscar Miró and Ana García Sarasola have equally contributed to this study and should both be considered as first author.

Address for correspondence:

Òscar Miró, MD, PhD

Emergency Department

Hospital Clínic

Villarroel 170

08036 Barcelona

Catalonia, Spain

FAX number: 34.93.227.56.93

Phone number: 34.93.227.98.33

Email: vgil@clinic.cat 
Acknowledgements: This study was partially supported by competitive grants from the Instituto de Salud Carlos III supported with funds from the Spanish Ministry of Health and FEDER (PI15/01019, PI15/00773, PI18/00393, PI18/00456), Catalonia Government (SGR 2009/1385, 2014/0313, 2017/1424), and Fundació La Marató de TV3 (2015/2510). The ICA-Research Group has received unrestricted funding from Novartis and Orion Pharma. The design of the study, patient inclusion, data analysis, discussion and final conclusions were exclusively carried out by the authors with no participation of the granters. We thank Alicia Díaz her professionalism in data management of the NOVICA cohort.

Investigators of the ICA-SEMES (Research group on Acute Heart Failure of the Spanish Society of Emergency Medicine): Marta Fuentes, Cristina Gil (Hospital Universitario de Salamanca), Héctor Alonso, Enrique PérezLlantada (Hospital Marqués de Valdecilla de Santander), Francisco Javier Martín-Sánchez, Guillermo Llopis García, Mar Suárez Cadenas (Hospital Clínico San Carlos de Madrid), Òscar Miró, Víctor Gil, Rosa Escoda, Carolina Xipell, Carolina Sánchez (Hospital Clínic de Barcelona), María José Pérez-Durá, Eva Salvo (Hospital Politénic La Fe de Valencia), José Pavón (Hospital Dr. Negrín de Las Palmas de Gran Canaria), Antonio Noval (Hospital Insular de Las Palmas de Gran Canaria), José Manuel Torres (Hospital Reina Sofía de Córdoba), María Luisa López-Grima, Amparo Valero, María Ángeles Juan (Hospital Dr. Peset de Valencia), Alfons Aguirre, Maria Angels Pedragosa, Silvia Mínguez Masó (Hospital del Mar de Barcelona), María Isabel Alonso, Francisco Ruiz (Hospital de Valme de Sevilla), José Miguel Franco (Hospital Miguel Servet de Zaragoza), Ana Belén Mecina (Hospital de Alcorcón de Madrid), Josep Tost, Marta Berenguer, Ruxandra Donea (Consorci Sanitari de Terrassa), Susana Sánchez Ramón, Virginia Carbajosa Rodríguez (Hospital Universitario Rio Hortega de Valladolid), Pascual Piñera, José Andrés Sánchez Nicolás (Hospital Reina Sofía de Murcia), Raquel Torres Garate (Hospital Severo Ochoa de Madrid), Aitor Alquézar-Arbé, Miguel Alberto Rizzi, Sergio Herrera (Hospital de la Santa Creu y Sant Pau de Barcelona), Javier Jacob, Alex Roset, Irene Cabello, Antonio Haro (Hospital Universitari de Bellvitge de Barcelona), Fernando Richard, José María Álvarez Pérez, María Pilar López Diez (Hospital Universitario de Burgos), Pablo Herrero Puente, Joaquín Vázquez Álvarez, Belén Prieto García, María García García, Marta Sánchez González (Hospital Universitario Central de Asturias de Oviedo), Pere Llorens, Patricia Javaloyes, Víctor Marquina, Inmaculada Jiménez, Néstor Hernández, Benjamín Brouzet, Begoña Espinosa (Hospital General de Alicante), Juan Antonio Andueza (Hospital General Universitario Gregorio Marañón de Madrid), Rodolfo Romero (Hospital Universitario de Getafe de Madrid), Martín Ruíz, Roberto Calvache (Hospital de Henares de Madrid), María Teresa Lorca Serralta, Luis Ernesto Calderón Jave (Hospital del Tajo de Madrid), Beatriz Amores Arriaga, Beatriz Sierra Bergua (Hospital Clínico Lozano Blesa de Zaragoza), Enrique Martín Mojarro, Brigitte Silvana Alarcón Jiménez (Hospital Sant Pau i Santa Tecla de Tarragona), Lisette Travería Bécquer, Guillermo Burillo (Hospital Universitario de Canarias de Tenerife), Lluís Llauger García, Gerard Corominas LaSalle. (Hospital Universitari de Vic de Barcelona), Carmen Agüera Urbano, Ana Belén García Soto, Elisa Delgado Padial (Hospital Costa del Sol de Marbella de Málaga), Ester Soy Ferrer (Hospital Josep Trueta de Girona). José Manuel Garrido (Hospital Virgen Macarena de Sevilla), Francisco Javier Lucas-Imbernón (Hospital General Universitario de Albacete), Rut Gaya (Hospital Juan XXIII de Tarragona), Carlos Bibiano, María Mir, Beatriz Rodríguez (Hospital Infanta Leonor de Madrid), José Luis Carballo (Complejo Hospitalario Universitario de Ourense), Esther Rodríguez-Adrada, Belén Rodríguez Miranda (Hospital Rey Juan Carlos de Móstoles de Madrid). 


\section{ABSTRACT (301 words)}

Objectives: We investigated the natural history of patients after a first episode of acute heart failure (AHF), focused on: 1) frequency of emergency department (ED) visits and hospitalizations; 2) departments admitting patients during first and subsequent hospitalizations; and 3) factors associated with difficult disease control after being discharged after de novo AHF (DNAHF) episode.

Methods: We included consecutive patients with DNAHF diagnosed in 4 ED located in Barcelona (Spain) at three time-points $(2009,2011,2014)$. We recorded clinical characteristics at index event, all post-discharge ED visits and hospitalizations (related and unrelated to AHF) until patient death or censure, and departments in charge of patients' hospitalization (during index event and subsequently). We defined patients as having "Uncontrolled disease" during the first year after index event discharge if they were attended at ED ( $\geq 3$ times) or hospitalized ( $\geq 2$ times) for AHF or died.

Results: We included 505 unique DNAHF patients followed up for 1,203 patient/year. In-hospital mortality during the index episode was 7.5\%. Among patients 467 discharged alive, 288 died (median survival time 3.9 years, $95 \% \mathrm{Cl}$, 3.5-4.4), 2,342 ED visits (42.4\% requiring hospitalization; $34.0 \%$ AHF-related) and 1,054 unplanned hospitalizations (94.1\% through ED; 51.4\% AHF-related) took place. Main departments involved in AHF-related hospitalizations were internal medicine $(28.0 \%)$, short-stay unit (26.3\%), cardiology (20.8\%), geriatrics (14.1\%) and intensive care units (2.8\%). Only $47.4 \%$ of HF-related rehospitalizations were at the same department as the DNAHF index hospitalization, and internal medicine involvement had a significant increment as subsequent admissions occur ( $p=0.01$ ). Uncontrolled disease was observed in $31.0 \%$ of patients, and was related to age $>80$ (adjusted OR $1.80 ; 1.17-2.77$ ) and ischemic cardiomyopathy as comorbidity (1.61, 1.03-2.53).

Conclusion: The natural history after DNAHF is by the very first time presented and shows different patterns of hospital department involvement and factors related to uncontrolled disease during the year after debuting. 


\section{INTRODUCTION}

Heart failure (HF) constitutes the common final syndrome for several specific cardiac diseases. Its natural history is characterized by multiple acute decompensations and progressive decline in heart function finally causing patient death. In many cases, HF remains undiagnosed until the development of a first episode of decompensation uncovers it. In fact, episodes of acute heart failure (AHF) are critical steps in the natural history of $\mathrm{HF}$, as they associate a high in-hospital mortality (between 5-10\% depending on the series) and shortly after patient discharge (with up to $20 \%$ of mortality following the following 90 days) ${ }^{2-4}$. In fact, a generic post-hospital syndrome has been recently defined to underline that patients who have recently been hospitalized are not only recovering from their acute illness, but they also experience a transient period of generalized risk for a wide range of adverse health events ${ }^{5}$. In the specific case of AHF, causes of rehospitalisation within 30 days are only related to HF in $35-37 \%$ of cases ${ }^{6,7}$.

However, there is a lack of studies analysing the natural history of patients after being diagnosed with a first episode of AHF. Some reasons have made difficult to have reliable data from the previous registries. First, most registries include AHF patients in a different evolutionary state of disease, mixing patients with a first episode with patients with advanced disease and multiple previous decompensations ${ }^{2-4,8}$. This associates a high patient heterogeneity that could bias interpretations, especially when analysing outcomes, even after further statistical adjustments, and this mixture of AHF patients has been proposed as a relevant confounding factor in clinical trials ${ }^{9}$. Second, although specific comparisons have been performed between de novo and acutely-decompensated $\mathrm{HF}^{10-13}$, and even registries exclusively including patients with a de novo AHF episode exist $^{14}$, they only include hospitalized patients, sometimes just coming from a single hospital department. This imposes the bias of hospitalization, and disregard the subset of AHF patients that are seen at the emergency department (ED, the place where the majority of them are seen first) and are directly discharged home without hospitalization (between one sixth and one third, depending on the countries) ${ }^{15}$. And third, there are no registries with a long-lasting patient follow-up period, as all the previously published series including de novo AHF patients consisted on cross-sectional descriptive analysis of patients' characteristics and outcomes exclusively corresponding to such a first AHF episode. Information of the subsequent AHF episodes is also important because, although involvement of the same hospital department in every patient hospitalization could be advisable, a patient transfer among specialities sometimes occurs. This is due because of, as in other long-lasting syndromes, the approach to a HF patient is multidisciplinary by definition and some health care providers and medical specialities participate in patient management ${ }^{16,17}$. Therefore, only a longitudinal approach can provide a real outlook in the natural history of HF and uncover the real interrelations between specialties taking care of AHF patient management.

All these considerations described above prompted us to launch the present study. The main objective was to evaluate, in a homogenous cohort of patients with a prolonged follow-up period, the natural history of HF patients after debuting with a first AHF episode, with special focus on: 1) the frequency of ED visits and hospitalizations, related and unrelated with AHF; 2) the main departments responsible of patient admissions 
during the first and subsequent hospitalizations due to AHF; and 3) the factors associated with a difficult control of patients (i.e., early need for ED revisits or rehospitalizations or death) once they have been discharged after de novo AHF episode. 


\section{METHODS}

Setting

The NOVICA-3 (apocopate from the Spanish words "De novo Insuficiencia Cardiaca Aguda"; in English: de novo AHF) study was designed as an exploratory, secondary analysis within the EAHFE Registry. The EAHFE Registry was initiated in 2007 and every 2-3 years carries out a 1-2-month recruitment period of all consecutive patients diagnosed with AHF in Spanish EDs participating in the project. To date, 6 recruitment phases (2007, 2009, 2011, 2014, 2016 and 2018) have been performed with the participation of 45 EDs from community and university hospitals across Spain (representing about 15\% of the Spanish public health care system hospitals), enrolling a total of 18,370 AHF patients. Details of patient inclusion have been reported previously ${ }^{3,18,19}$. Briefly, patient enrolment is done by any attending emergency physician in the participating EDs, who receives specific study protocol instructions during a weekly ED meeting preceding patient recruitment. These physicians are responsible for the detection of potential cases of AHF. All suspected cases are confirmed by the principal investigator of each centre to ensure the patients meet the diagnostic criteria of $\mathrm{AHF}$ based on the Framingham clinical criteria ${ }^{20}$. If possible, the diagnosis is also confirmed by measurement of plasma natriuretic peptide and/or echocardiography during ED or hospital stay following the current ESC guideline recommendations (which occurs in about $92 \%$ of cases) ${ }^{21}$. The principal investigator of each centre is responsible for the final diagnostic adjudication of the cases. The only exclusion criterion for being included into the EAHFE Registry is a primary diagnosis of ST-elevation myocardial infarction (STEMI) while concurrently developing AHF (which occurs in about 3\% of AHF cases), as the majority of these patients bypass the ED and go directly to the catheterization laboratory. The EAHFE Registry does not include any planned intervention, and the management of patients is entirely based on the attending ED physician decisions. However, all of these physicians are aware of the ESC guidelines, which are the main reference for all emergency physician actions.

Ethics

The EAHFE Registry protocol was approved by a central Ethics Committee at the Hospital Universitario Central de Asturias (Oviedo, Spain) with the reference numbers 49/2010, 69/2011, 166/13, 160/15 and 205/17. Due to the non-interventional design of the registry, Spanish legislation allows central Ethical Committee approval, accompanied by notification to the local Ethical Committees. All participating patients gave informed consent to be included in the registry and to be contacted for follow up. The NOVICA-3 study was carried out in strict compliance with the Declaration of Helsinki principles. The authors designed the study, gathered, and analysed the data, vouched for the data and analysis, wrote the paper, and decided to publish.

\section{Design and variables recorded}

We selected four tertiary university hospitals providing patients to the EAHFE registry that serve adjacent health care areas of Barcelona (Catalonia, Spain): Hospital Universitari de Bellvitge, Hospital Clínic, Hospital de la Santa Creu i Sant Pau, and Hospital del Mar. The assigned population for heatlh coverage for these four 
hospitals is 2,2 million people out of the 3.1 million people conforming the first Barcelona's metropolitan crown. With this strategy, we wanted to obtain a homogeneous population coming from a continuous geographical territory served by neighbouring hospitals, as patients from urban zones with more than one hospital sometimes ask for urgent care to different hospitals. In addition, all four hospitals share the same electronic system for medical record repository (HC3, Història Clínica Compartida de Catalunya), which is supported by the public health provider (Catalonian Department of Health) and it can be accessed online by medical professionals involved in the patient care.

The NOVICA-3 study was designed to explore the natural history of AHF patients who had presented to ED of one of the four hospitals involved in the study complaining with the first episode of decompensation (de novo AHF). The NOVICA-3 study was specially focused on the episodes of ED revisits and hospitalizations following such first episode. With this purpose, the NOVICA-3 study included patients with a de novo AHF episode recruited in the EAHFE Registry phases 2 (2009), 3 (2011) and 4 (2014), for whom the expected follow up length at the time of the study initiation (June 2016) was longer than 1 year. Phase 1 patients (2007) were discarded because of some key variables were not recorded at that moment, phase 5 patients (2016) because of they did not have enough time on follow up at the time of study initiation, and phase 6 patients (2018) because of they had not been included in the registry yet. In all cases, patients were followed up from the index event (de novo AHF diagnosis at ED) until death or the end of follow up, which was fixed at the time of the patient's medical records review. Such medical reviews were performed between June 2016 to September 2017, and consisted in individual revision of all the medical records of every patient in any of the four participating hospitals and also at any hospital of Catalonia (Spain), as the HC3 gets access to all the medical records produced at any of the 58 Catalonian public hospitals.

Twenty-six independent variables were recorded, including demographic data (2 variables), comorbidities (13 variables), baseline status ( 3 variables), triggers of the AHF episode (6 variables) and severity of the AHF index episode (2 variables) (see Supplemental Table 1 for definitions). Regarding the two variables assessing the severity of de novo AHF episode, they consisted in: 1) the calculation of the MEESSI risk score for every patient, as this risk score has recently been reported to accurately estimate the risk of death during the following 30 days in patients diagnosed with $\mathrm{AHF}$ in the $\mathrm{ED}^{18,22,23}$, and 2) the consignation of the need of hospitalization during the index episode.

\section{Outcomes}

For every patient, we recorded the following outcomes: 1) every ED revisit, and if the revisit was or was not related to an AHF episode; 2) every patient hospitalization (irrespective whether it was elective or urgent), and if the hospitalization was or was not related to an AHF episode, and the department where hospitalization took place; and 3) the vital status of the patient at the end of the study (live or dead). Death and the number of ED visits and hospitalizations due to AHF episodes were used to detect patients with difficult control of signs and symptoms of HF. In this sense, we defined "Uncontrolled disease" as patients that need to consult an ED due to AHF at least 3 times (irrespective if patients was finally hospitalized or was 
not), to hospitalize at least 2 times due to AHF (irrespective it was through ED or was not) or died in the year after de novo AHF index discharge. Accordingly, patients that died during the index episode (in-hospital mortality) were excluded for this specific analysis. Follow-up was performed through telephone contact during the first year and thereafter by consultation of both, the in-site hospital electronic records and the online HC3 regional electronic system. Adjudication of events was made at an at-site level by two investigators and, in cases with discrepancy, the principal investigator discussed the case until final agreement was achieved.

\section{Statistical analysis}

Continuous variables are expressed as mean and standard deviation (SD) or median and interquartile range (IQR) if not normally distributed, and discrete variables as absolute values and percentages. Comparison among groups was carried out using one-way ANOVA or the Mann-Whitney non-parametric test for continuous variables and the chi square test (for trend, when needed) for discrete variables. Survival tables were obtained and Kaplan-Meier curves were plotted for the first post-discharge ED visit or hospitalization (overall and related to AHF) and for all-cause death. The risk of having uncontrolled disease the year after index event discharge was expressed by odds ratio (OR) calculated by logistic regression, first unadjusted and then adjusted with a multivariate model that included all the variables that showed a significant association in the univariate analysis. Missing values were replaced using the multiple imputation technique, generating 5 datasets with no missing values for the variables included in the final adjusted model. Further adjustment at centre level was also included. Due to the exploratory nature of our investigation, a pre-hoc sample size calculation was not made. Statistical significance was accepted if the 95\% confidence interval (Cl) of the $\mathrm{HR}$ excluded the value 1 , or the $p$ value was less than 0.05 


\section{RESULTS}

The NOVICA-3 study finally included 505 patients in the analysis (Figure 1). The mean age was 80 (SD=10) years, and $51.8 \%$ were women. The most frequent comorbidities were hypertension (81\%), dyslipidaemia (46\%), diabetes (38\%) and atrial fibrillation (36\%). The rest of clinical characteristics are presented in the Table 1. Precipitants of the index episode were recognised in $70 \%$ of cases, and the most frequent was infection, detected in $26 \%$ of cases. With respect to the severity of the acute episode, $59 \%$ were classified by the MEESSI scale as low risk, $25 \%$ as intermediate risk, $11 \%$ as high risk and $5 \%$ as very high risk. Overall, $64 \%$ of patients were hospitalized during the index episode, and the main departments where hospitalization took place during the first AHF episode were: short stay unit (30\%), cardiology (22\%), internal medicine (20\%) and geriatrics (10\%). Only $3 \%$ of cases required intensive care admission (Figure 1 ).

The follow up for the whole cohort of 505 patients extended 1,203 patient/year (2.4 years/patient), and the median and mean survival times were 3.78 (3.28-4.27) years and 3.87 (3.56-4.17) years, respectively. Thirtyeight patients died during the index episode (in-hospital mortality 7.5\%), and we could follow up 466 out of the 467 remaining patients that were discharged alive (283 after hospitalization and 183 directly discharged from the ED), with a mean follow up time of 2.6 years/patient. During the follow up of these patients, 223 deaths happened, and the median survival time was 3.93 (3.47-4.39) years (Figures 1 and 2).

After the index event, we registered 2,342 ED visits (34\% related to AHF episodes), with a median time for the first ED post-discharge visit of 80 (55-102) days [434 (314-555) days for the first AHF-related ED visit). A $42 \%$ of these ED revisits needed patient hospitalization, and this was more frequent in AHF-related than in AHFunrelated ED visits (66\% vs. $30 \%$; p $<0.001$ ). On the other hand, we registered 1,054 hospitalizations $(51 \%$ related to AHF), and 992 (93.6\%) accounted after ED consultation. With respect to 542 post-discharge AHFrelated hospitalizations, 528 (97.4\%) occurred after an ED visit (the resting $2.6 \%$ of patients were directly hospitalized proceeding from walk-in centres, and were not evaluated at the ED before admission to hospital wards). The median time for the first hospitalisation after being discharged from the AHF index episode was 285 (226-347) days [850 (569-1131) days for the first AHF-related hospitalization] (Figures 1 and 2).

There were 283 patients hospitalized during the index episode and discharged alive. For them, departments involved in further hospitalizations due to new AHF episodes did not change significantly, with the exception of internal medicine department, which increased the proportion of admitted patients as the number of hospitalization increased ( $p=0.01$, Figure 3). When we specifically analysed the 263 patients initially managed in one of the four main departments responsible of the first AHF admission (short-stay unit, cardiology, internal medicine and geriatrics), we found that $47.4 \%$ of rehospitalizations took place at the same department where patient was hospitalized during the index event, with no statistically significant differences among them (Figure 4, top). Similarly, there were no statistically significant changes in the percentage of hospitalizations carried out by the department responsible of the index admission as the number of hospitalizations progressively increased (Figure 4, down). 
A total of 462 out of the 466 patients discharged alive after the index AHF event could be classified according to definition of controlled/uncontrolled disease proposed by us (in the 4 remaining cases the patient was alive but with a follow-up of less than 1 year): 319 were classified as having a controlled disease (69\%) and $143(31 \%)$ as uncontrolled disease. Six factors were associated with uncontrolled disease in the unadjusted analysis, but only two remained significant after adjustment: age $>80$ (OR 1.80; 1.17-2.77) and ischemic cardiomyopathy as comorbidity $(1.61,1.03-2.53)$ (Table 2). Further adjustment by hospital level retrieved nearly identical results (Table 2). 


\section{DISCUSSION}

The NOVICA-3 study is the first longitudinal analysis with a long-lasting follow-up of a cohort of unselected patients after debuting with a first episode of $A H F$, and three main findings have to be highlighted. First, patients discharged alive after de novo AHF has a median survival time of 3.9 years, with median times for first AHF-related ED visit and AHF-related hospitalization of 434 and 850 days, respectively. Second, departments involved in patient hospitalizations during de novo AHF episode are diverse, and similar proportion of patients are managed by the three most frequently involved ones (short-stay unit, cardiology and internal medicine, which take care of between $20 \%$ and $30 \%$ of admissions each one). Significant increase in hospitalizations in the internal medicine department was noted along the natural history of HF. Nonetheless, less than $50 \%$ of rehospitalizations took place at the same department where patients were first hospitalized during the index event. And third, close to one third of patients had a difficult management of HF during the year following the first de novo AHF episode, which was more frequently seen for patients at advanced age and with a previous history of ischaemic cardiomyopathy.

The first hospitalization due to AHF represents an inflection point in the natural history whereby subsequent all-cause mortality risk following discharge has been reported to be 3-fold higher than in patients with HF that have never been hospitalized ${ }^{24}$. In a community study, Dunlay et al. reported that $67 \%$ of HF experienced 2 or more hospitalizations (and 43\%, 4 or more) during a median follow up period of 4.7 years ${ }^{25}$. In fact, hospitalizations represent $77 \%$ of the lifetime medical costs in patients with $\mathrm{HF}^{26}$. In our series, the mean of hospitalizations per patient was 3.1 during a mean follow up of 2.4 years, which is close the previous reported figures. On the other hand, the median time for post-discharge all-cause mortality was 3.9 years, and 5-year mortality was $61.0 \%$. Our findings are also close to previous long term estimations in other series of de novo $\mathrm{AHF}$, that ranged from $47.4 \%{ }^{27}$ to ..., ${ }^{28}$ although these data come from hospitalized patients. It has to be underlined that survival time since HF diagnosis should be somehow longer than we are reporting, as part of patients debuting with AHF could have been diagnosed with HF previously, and this data was not recorded in the present study.

Departments involved in AHF hospitalizations were diverse in our study. It is remarkably that proportion of hospitalization during the index and subsequent decompensations was maintained quite stable, with the only exception of internal medicine that progressively took care of a higher proportion of patients as the number of hospitalizations progressively increased. Probably, our aged population, with a high number of comorbidities, significant degree of physical dependence being present in $42 \%$ of patients and more than a half of patients having preserved left ventricular ejection fraction influenced the increasing role of internal medicine as $\mathrm{HF}$ evolves and patient requires repeated hospitalizations. It is also noticeable than less than half of patients are rehospitalized at the same department where patient was managed during the index episode. We did not investigate the causes of that, as we did not assess if that was associated with a proper hand-over among specialists or what circumstances influenced in this exchange. The effect of being controlled by the same team along all the disease natural history on outcomes has not specifically explored previously. It is well 
accepted that transition of patients after decompensation plays a central role in obtaining the best results. A very recent meta-analysis of 41 randomised trials testing transitional care interventions demonstrated that implementation of transitional plans at AHF patient discharge achieves a significant reduction of $8 \%$ and $29 \%$ in the risk of rehospitalisation and ED visits, respectively ${ }^{29}$. In addition, another recent meta-analysis described the benefits of heart failure clinics in reducing hospitalisation for AHF and all-cause mortality, which was greater among patients with recent ED visit or hospitalisation due to decompensation ${ }^{30}$. We believe that investigation of the effects of long-time management by the same medical team on outcomes of patients with HF remains to be investigated.

Uncontrolled disease was seen in about one third of patients. We define uncontrolled disease by the presence of repeated ED visits $(\geq 3)$ or hospitalization $(\geq 2)$ due to AHF or death during the year following discharge after the de novo AHF episode. A very recent paper, Go YY et al., using proper methodology to isolated the effects of hospitalizations apart of the influence of death (an important confounder in readmission analysis), established the definition of frequent admitters for those patients with AHF having $\geq 2$ AHF-related hospitalizations/year ${ }^{31}$, and demonstrated that this subset of patients had longer length of stay, higher economic costs and higher all-cause mortality during a 3-year follow up period. In fact, Solomon et al. have demonstrated that the risk of death increases with each additional HF hospitalization, with a nearly $30 \%$ cumulative incremental risk associated with discharge from a second or third HF, and additionally, they also found that risk of mortality is clearly higher during the first 12 months after hospital discharge for such first AHF episode ${ }^{24}$. They, however, did not explore related factors with this profile more prone to have decompensations and adverse outcomes. We have seen that patients with advanced age and ischaemic cardiomyopathy as comorbidity are at increased risk of having uncontrolled disease after debuting with AHF. Hypothetically, other factors could be associated with lack of proper disease control, although the exploratory nature of present study precludes obtaining a more solid result. Interestingly, the lack of hospitalization during the index AHF event, a fact that accounted in $36 \%$ of our patients, did not predispose to uncontrolled disease. In fact, as commented previously, if an actionable plan for transition and a proper follow-up track exist, good results can be achieved in less severe decompensated patients managed in ambulatory care ${ }^{29,30}$.

The NOVICA-3 has a number of limitations. First, this real life cohort without intervention, and attending physicians followed their usual local protocols and did not receive any specific instructions about the precise time for ED or hospital discharge and patient transition. Second, the diagnosis of AHF was based on clinical criteria, and in some cases the final diagnosis of AHF was not supported in all cases by natriuretic peptide or echocardiographic results. Although these two limitations could impose caution in interpretation of some of our conclusions, they otherwise make our findings more generalizable to the real world practice. Third, although the patients were from a single city with a universal public healthcare system and participating hospitals were located one next to other, national and international heterogeneity in organizational and 
transition processes is high ${ }^{32}$; therefore, our results should be confirmed in other cities and, specially, in other countries with different healthcare system models. Fourth, this is an observational study and causal relationships cannot be inferred. This specially applies to the investigation of factors related to uncontrolled disease. Our results relating age and ischaemic cardiomyopathy with uncontrolled disease have to be confirmed by studies specifically designed to identify such relationships. And fifth, since there was no sample size calculation due to the exploratory nature of the study, a type-II error cannot be excluded in some of the estimations made. For example, the trend for decreasing participation of short-stay units as subsequent AHF hospitalizations are needed, or the non-significant increase in risk of uncontrolled disease related to chronic kidney failure (+60\%), NYHA class III-IV at baseline (+76\%) or increased risk MEESSI category during acute decompensation $(+60 \%)$, could really exist and become statistically significant if a large number of patients would have been included.

As conclusion, the natural history after de novo AHF is by the very first time presented and shows different patterns of hospital department involvement, with increasing participation of internal medicine department in hospitalizations. In addition, factors like advanced age and ischaemic cardiomyopathy seems to be related to lack of proper disease control during the year after debuting. 


\section{REFERENCES}

\section{1.- Natural history of HF}

2.- Chioncel O, Mebazaa A, Harjola VP, Coats AJ, Piepoli MF, Crespo-Leiro MG, et al. Clinical phenotypes and outcome of patients hospitalized for acute heart failure: the ESC Heart Failure Long-Term Registry. Eur J Heart Fail. 2017; 19:1242-1254.

3.- Llorens P, Javaloyes P, Martín-Sánchez FJ, Jacob J, Herrero-Puente P, Gil V, et al. Time trends in characteristics, clinical course, and outcomes of 13,791 patients with acute heart failure. Clin Res Cardiol. 2018; 107:897-913.

\section{4.- Mortality on American or Canadian series}

5.-Krumholz HM. Post-hospital syndrome. A condition of generalized risk. N Engl J Med 2013; 368:100-2.

6.-Jenks SF, Williams MV, Coleman EA. Rehospitalizations among patients in the Medicare fee-for-service program. N Engl J Med 2009; 360:1418-28

7.- Dharmarajan K, Hsieh AF, Lin Z, Bueno H, Ross JS, Horwitz LI, Barreto-Filho JA, Kim N, Bernheim SM, Suter LG, Drye EE, Krumholz HM. Diagnoses and timing of 30-day readmissions after hospitalization for heart failure, acute myocardial infarction, or pneumonia. JAMA 2013; 309:355-63.

\section{8.- EFFECT}

9.- Greene SJ, Hernandez AF, Dunning A, Ambrosy AP, Armstrong PW, Butler J, et al. Hospitalization for Recently Diagnosed Versus Worsening Chronic Heart Failure: From the ASCEND-HF Trial. J Am Coll Cardiol. 2017; 69:3029-3039.

10.- Lassus JP, Siirilä-Waris K, Nieminen MS, Tolonen J, Tarvasmäki T, Peuhkurinen K, et al. Long-term survival after hospitalization for acute heart failure--differences in prognosis of acutely decompensated chronic and new-onset acute heart failure. Int J Cardiol. 2013; 168:458-62.

11.- Senni M, Gavazzi A, Oliva F, Mortara A, Urso R, Pozzoli M, et al. In-hospital and 1-year outcomes of acute heart failure patients according to presentation (de novo vs. worsening) and ejection fraction. Results from IN-HF Outcome Registry. Int J Cardiol. 2014; 173:163-9.

12.- Choi KH, Lee GY, Choi JO, Jeon ES, Lee HY, Cho HJ, et al. Outcomes of de novo and acute decompensated heart failure patients according to ejection fraction. Heart. 2018; 104:525-532.

13.- AlHabib KF, Kashour T, Elasfar AA, Alfaleh H, Hersi A, Alshamiri M, et al. Long-Term Mortality Rates in Acute De Novo Versus Acute-on-Chronic Heart Failure: From the Heart Function Assessment Registry Trial in Saudi Arabia. Angiology. 2015; 66:837-44.

14.- Franco J, Formiga F, Corbella X, Conde-Martel A, Llácer $P$, Álvarez Rocha $P$, et al. De novo acute heart failure: Clinical features and one-year mortality in the Spanish nationwide Registry of Acute Heart Failure. Med Clin (Barc). 2019; 152:127-134.

15.- Miró Ò, Levy PD, Möckel M, Pang PS, Lambrinou E, Bueno H, et al. Disposition of emergency department patients diagnosed with acute heart failure: an international emergency medicine perspective. Eur J Emerg Med. 2017; 24:2-12.

16.- Formiga F, Chivite D. Acute heart failure: Understanding the patient is essential. Emergencias. 2018; 30:145-6. 
17.- Harjola P, Harjola VP. Can we do more for patients with acute heart failure before arrival at the hospital? Emergencias. 2017;29:221-2.

18.- Miró Ò, Rossello X, Gil V, Martín-Sánchez FJ, Llorens P, Herrero-Puente P, et al. Predicting 30-day mortality for patients with acute heart failure in the emergency department: A cohort study. Ann Intern Med 2017; 167:698-705.

19.- Miró O, Llorens P, Escalada X, Herrero P, Jacob J, Gil V, et al. Prehospital emergency care of patients with acute heart failure in Spain: the SEMICA study (Emergency Medical Response Systems for Patients with Acute Heart Failure). Emergencias. 2017;29:223-30.

20.- Ho KKL, Anderson KM, Kannel WB, Grosssman W, Levy D. Survival after the onset of congestive heart failure in Framingham heart study subjects. Circulation 1993; 88:107-15.

21.- Ponikowski P, Voors AA, Anker SD, Bueno H, Cleland JG, Coats AJ, et al. 2016 ESC Guidelines for the diagnosis and treatment of acute and chronic heart failure: The Task Force for the diagnosis and treatment of acute and chronic heart failure of the European Society of Cardiology (ESC). Developed with the special contribution of the Heart Failure Association (HFA) of the ESC.Eur Heart J. 2016; 37:2129-200.

22.- Miró Ò, Gil V, Rosselló X, Martín-Sánchez FJ, Llorens P, Jacob J, et al. Patients with acute heart failure discharged from the emergency department and classified as low risk by the MEESSI score (multiple risk estimate based on the Spanish emergency department scale): prevalence of adverse events and predictability. Emergencias. 2019; 31:5-14.

23.- Wussler D, Kozhuharov N, Sabti Z, Walter J, Strebel I, Scholl L, et al. External Validation of the MEESSI Acute Heart Failure Risk Score: A Cohort Study. Ann Intern Med. 2019 (in press). doi: 10.7326/M18-1967.

24.- Solomon SD, Dobson J, Pocock S, Skali H, McMurray JJ, Granger CB, et al. Candesartan in Heart failure: Influence of nonfatal hospitalization for heart failure on subsequent mortality in patients with chronic heart failure. Circulation 2007; 116:1482-7.

25.- Dunlay SM, Redfield MM, Weston SA, ThernauTM, Hall Long K, Shad ND, et al. Hospitalizations afterheart failure diagnosis. A community perspective. J Am Coll Cardiol 2009; 54:1695-1702.

26.- Dunlay SM, Shah ND, Shi Q, Morlan B, VanHoutenH, Long KH, et al. Lifetime costs of medical care after heart failure diagnosis. Circ Cardiovasc Qual Outcomes 2011; 4:68-75.

27.- Tolppanen H, Siirila-Waris K, Harjola VP, Marono D, Parenica J, Kreutzinger P, et al. Ventricular conduction abnormalities as predictors of long-term survival in acute de novo and decompensated chronic heart failure. ESC Heart Fail. 2016; 3:35-43.

\section{8.- Upper limit of 5 year mortality after debuting.}

29.- Vedel I, Khanassov V. Transitional care for patients with congestive heart failure: a systematic review and meta-analysis. Ann Fam Med. 2015; 13:562-71.

30.- Gandhi S, Mosleh W, Sharma UC, Demers C, Farkouh ME, Schwalm JD. Multidisciplinary heart failure clinics are associated with lower heart failure hospitalization and mortality: systematic review and metaanalysis. Can J Cardiol. 2017; 33:1237-1244.27.

31.- Go YY, Sellmair R, Allen Jr. AC, Sahlén A, Bulluck H, Sim D, et al. Defining a 'frequent admitter' phenotype among patients with repeat heart failure admissions. Eur J Heart Fail. 2019; 21:311-318 
32.- Bhatt AB, Cheeran DD, Shemisa K, Roy L, Manz BN, Vigen R, et al. Physician-specific practice patterns about discharge readiness and heart failure utilization outcomes. Circ Cardiovasc Qual Outcomes. 2018; 11:e004365. 
Table 1: Characteristics of the 505 patients included in the NOVICA cohort.

\begin{tabular}{|c|c|c|}
\hline & $\begin{array}{c}\text { Total } \\
\mathrm{N}=505 \\
\mathrm{n}(\%)\end{array}$ & $\begin{array}{l}\text { Missing } \\
\text { values } \\
\mathrm{n}(\%)\end{array}$ \\
\hline \multicolumn{3}{|l|}{ Demographic data } \\
\hline Age (grouped) & & $0(0)$ \\
\hline -Age $<60$ years & $26(5.1)$ & \\
\hline -Age $60-80$ years & $185(38.6)$ & \\
\hline -Age $>80$ years & $284(56.2)$ & \\
\hline Female & $261(51.8)$ & $1(0.2)$ \\
\hline \multicolumn{3}{|l|}{ Comorbidities } \\
\hline Hypertension & $407(80.6)$ & $0(0)$ \\
\hline Diabetes mellitus & $193(38.2)$ & $0(0)$ \\
\hline Dyslipidaemia & $234(46.3)$ & $0(0)$ \\
\hline Ischaemic heart disease & $136(26.9)$ & $0(0)$ \\
\hline Chronic kidney failure (creatinine $>2 \mathrm{mg} / \mathrm{mL}$ ) & $115(22.8)$ & $0(0)$ \\
\hline Cerebrovascular disease & $72(14.3)$ & $0(0)$ \\
\hline Atrial fibrillation & $180(35.6)$ & $0(0)$ \\
\hline Peripheral artery disease & $52(10.3)$ & $0(0)$ \\
\hline Heart valve disease & $111(22.0)$ & $0(0)$ \\
\hline Chronic obstructive pulmonary disease & $99(19.6)$ & $0(0)$ \\
\hline Dementia & $46(10.2)$ & $54(10.7)$ \\
\hline Active neoplasia & $79(17.5)$ & $54(10.7)$ \\
\hline Hepatic cirrhosis & $9(2.0)$ & $54(10.7)$ \\
\hline \multicolumn{3}{|l|}{ Baseline status } \\
\hline $\begin{array}{l}\text { Barthel Index (points) } \\
\text {-No or minimal dependence (Barthel index }>90 \text { points) } \\
\text {-Mild to moderate dependence (Barthel index } 90-50 \text { points) } \\
\text {-Severe or total dependence (Barthel index }<50 \text { points) }\end{array}$ & $\begin{array}{c}250(58.3) \\
150(35.0) \\
29(6.8)\end{array}$ & $76(15.0)$ \\
\hline $\begin{array}{l}\text { NYHA class } \\
-I \\
-I I \\
-I I I \\
-I V \\
\end{array}$ & $\begin{array}{c}176(37.9) \\
240(51.7) \\
45(9.3) \\
3(0.6) \\
\end{array}$ & $41(8.1)$ \\
\hline $\begin{array}{l}\text { Left ventricular ejection fraction (LVEF, \%) } \\
\text {-LVEF }<40 \% \\
\text {-LVEF } 40-49 \% \\
\text {-LVEF } \geq 50 \%\end{array}$ & $\begin{array}{l}61(18.7) \\
40(12.2) \\
226(69.1)\end{array}$ & $178(35.2)$ \\
\hline \multicolumn{3}{|l|}{ Triggering factor for the current AHF episode } \\
\hline Infection & $112(25.7)$ & $69(13.7)$ \\
\hline Rapid atrial fibrillation & $81(16.8)$ & 69 (13.7) \\
\hline Anaemia & $26(6.0)$ & $69(13.7)$ \\
\hline Hypertensive emergency & $37(8.5)$ & $69(13.7)$ \\
\hline Dietetic or therapeutic transgression & $16(3.7)$ & $69(13.7)$ \\
\hline Acute coronary syndrome & $15(3.0)$ & $12(2.4)$ \\
\hline \multicolumn{3}{|l|}{ Severity of the AHF episode } \\
\hline $\begin{array}{l}\text { MEESSI risk category } \\
\text {-Low risk } \\
\text {-Intermediate risk } \\
\text {-High risk } \\
\text {-Very high risk }\end{array}$ & $\begin{array}{c}211(59.1) \\
89(24.9) \\
38(10.6) \\
19(5.3) \\
\end{array}$ & $148(29.3)$ \\
\hline Need of hospitalization & $321(63.7)$ & $1(0.2)$ \\
\hline
\end{tabular}


Table 2: Analysis of variables related to uncontrolled disease for the 466 patients discharged alive after a de novo acute heart failure episode.

\begin{tabular}{|c|c|c|c|c|c|c|}
\hline & $\begin{array}{c}\text { Uncontrolled } \\
\text { disease } \\
\begin{array}{c}\mathrm{N}=143 \\
\mathrm{~N}(\%)\end{array}\end{array}$ & $\begin{array}{c}\text { Controlled } \\
\text { disease } \\
\mathrm{N}=319 \\
\mathrm{~N}(\%)\end{array}$ & $P$ value & $\begin{array}{l}\text { Unadjusted OR (95\% } \\
\text { CI) for uncontrolled } \\
\text { disease }\end{array}$ & $\begin{array}{l}\text { Adjusted OR (95\% } \\
\text { CI) for uncontrolled } \\
\text { disease }\end{array}$ & $\begin{array}{l}\text { Adjusted OR ( } 95 \% \mathrm{Cl}) \text { for } \\
\text { uncontrolled disease } \\
\text { (controlled by centre) }\end{array}$ \\
\hline \multicolumn{7}{|l|}{ Demographic data } \\
\hline Age $>80$ years & $95(66.4)$ & $157(49.2)$ & 0.001 & $2.04(1.35-3.08)$ & $1.80(1.17-2.77)$ & $1.81(1.18-2.80)$ \\
\hline Female & $79(49.0)$ & $166(52.2)$ & 0.52 & $0.89(0.59-1.30)$ & - & - \\
\hline \multicolumn{7}{|l|}{ Comorbidities } \\
\hline Hypertension & $119(83.2)$ & $250(78.4)$ & 0.23 & $1.40(0.82-2.29)$ & - & - \\
\hline Diabetes mellitus & $63(44.1)$ & $114(35.7)$ & 0.09 & $1.42(0.95-2.12)$ & - & - \\
\hline Dyslipidaemia & $63(44.1)$ & $154(48.3)$ & 0.40 & $0.84(0.57-1.25)$ & - & - \\
\hline Ischaemic heart disease & 49 (34.3) & $73(22.9)$ & 0.011 & $1.76(1.14-2.71)$ & $1.61(1.03-2.53)$ & $1.61(1.03-2.53)$ \\
\hline Chronic kidney failure (creatinine $>2 \mathrm{mg} / \mathrm{mL}$ ) & $38(26.6)$ & $66(20.7)$ & 0.16 & $1.39(0.88-2.20)$ & - & - \\
\hline Cerebrovascular disease & $30(21.0)$ & $39(12.2)$ & 0.016 & $1.91(1.13-3.22)$ & $1.61(0.93-2.80)$ & $1.62(0.94-2.82)$ \\
\hline Atrial fibrillation & $61(42.7)$ & $106(33.2)$ & 0.05 & $1.49(1.00-2.24)$ & - & - \\
\hline Peripheral artery disease & $19(13.3)$ & $27(8.5)$ & 0.11 & $1.66(0.89-3.09)$ & - & - \\
\hline Heart valve disease & $37(25.9)$ & $64(20.1)$ & 0.16 & $1.39(0.87-2.21)$ & - & - \\
\hline Chronic obstructive pulmonary disease & $21(14.7)$ & $67(21.0)$ & 0.11 & $0.65(0.38-1.11)$ & - & - \\
\hline Dementia & $15(11.4)$ & $19(6.8)$ & 0.12 & $1.77(0.87-3.60)$ & - & - \\
\hline Active neoplasia & $26(19.7)$ & $42(14.9)$ & 0.23 & $1.40(0.81-2.39)$ & - & - \\
\hline Hepatic cirrhosis & $3(2.3)$ & $4(1.4)$ & 0.54 & $1.61(0.35-7.30)$ & - & - \\
\hline \multicolumn{7}{|l|}{ Baseline status } \\
\hline More than minimal dependence (mild to total, Barthel index $\leq 90$ points) & $61(50.0)$ & $91(33.2)$ & 0.002 & $2.01(1.30-3.11)$ & $1.23(0.74-2.04)$ & $1.24(0.74-2.07)$ \\
\hline NYHA class III-IV & $20(15.2)$ & $21(7.1)$ & 0.011 & $2.33(1.22-4.47)$ & $1.76(0.88-3.55)$ & $1.73(0.86-3.50)$ \\
\hline Decreased left ventricular ejection fraction $(<50 \%)$ & $22(23.2)$ & $73(34.1)$ & 0.06 & $0.58(0.33-1.01)$ & - & - \\
\hline \multicolumn{7}{|l|}{ Triggering factor for the current AHF episode } \\
\hline Infection & $29(23.0)$ & $68(24.9)$ & 0.68 & $0.90(0.55-1.48)$ & - & - \\
\hline Rapid atrial fibrillation & $20(15.9)$ & $55(20.1)$ & 0.31 & $0.75(0.43-1.31)$ & - & - \\
\hline Anaemia & $11(8.7)$ & $13(4.8)$ & 0.13 & $1.91(0.83-4.40)$ & - & - \\
\hline Hypertensive emergency & $8(6.3)$ & $28(10.3)$ & 0.21 & $0.59(0.26-1.34)$ & - & - \\
\hline Dietetic or therapeutic transgression & $8(6.3)$ & $7(2.6)$ & 0.07 & $2.58(0.91-7.27)$ & - & - \\
\hline Acute coronary syndrome & $6(4.3)$ & $7(2.2)$ & 0.24 & $1.95(0.64-5.92)$ & - & - \\
\hline \multicolumn{7}{|l|}{ Severity of the AHF episode } \\
\hline Increased risk (intermediate/high/very high) according to MEESSI scale & $49(49.0)$ & $68(30.2)$ & 0.001 & $2.22(1.37-3.60)$ & $1.60(0.95-2.68)$ & $1.63(0.96-1.02)$ \\
\hline Need of hospitalization & $93(65.0)$ & $194(61.0)$ & 0.41 & $1.19(0.79-1.79)$ & - & - \\
\hline
\end{tabular}


Figure 1: Patient inclusion flow chart for the NOVICA cohort and distribution of patients along with the events registered after the first de novo acute heart failure (AHF) episode.

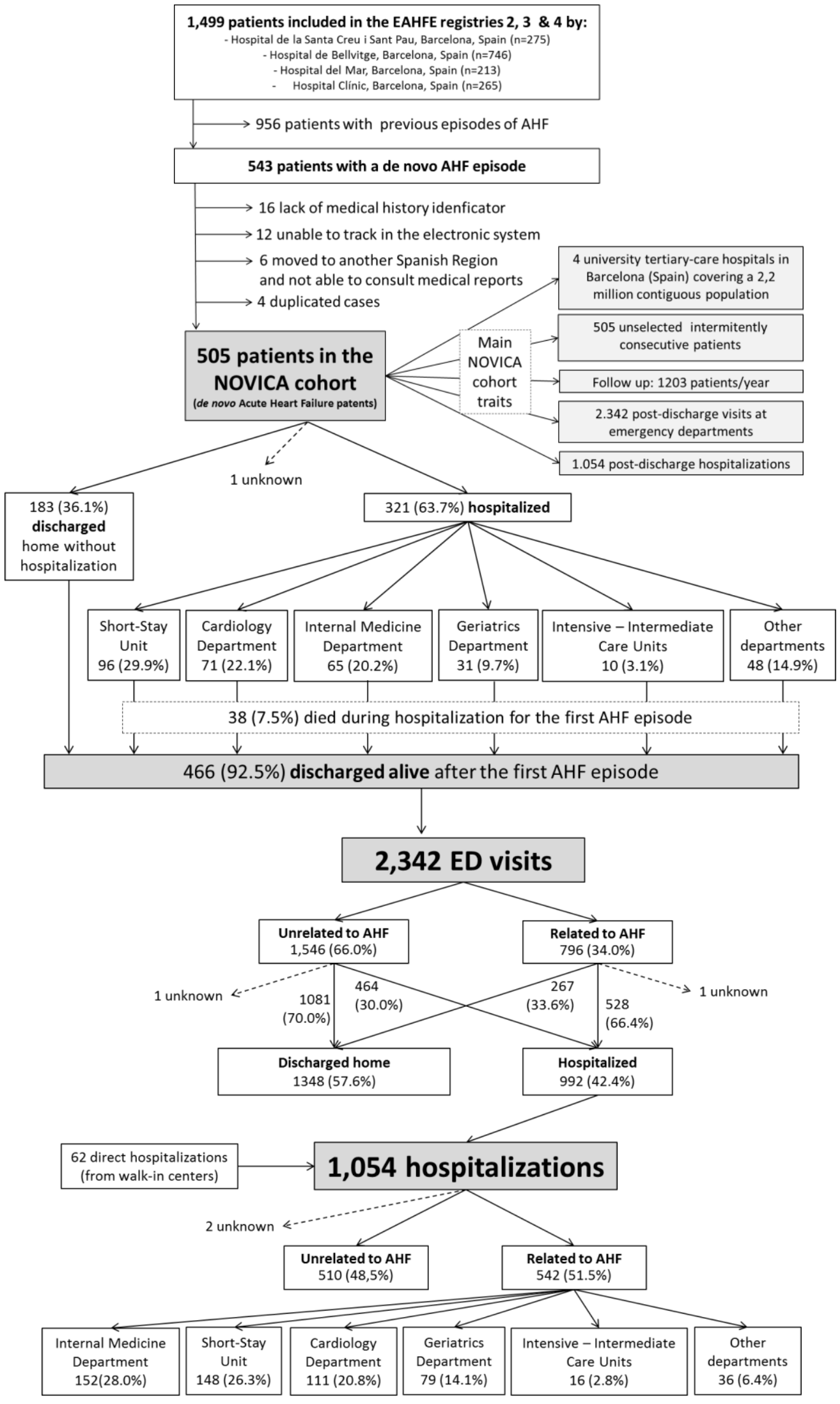


Figure 2: Survival curves for the three post-discharge outcomes (top: death; middle: hospitalization; down: emergency department visit) registered in the NOVICA cohort.
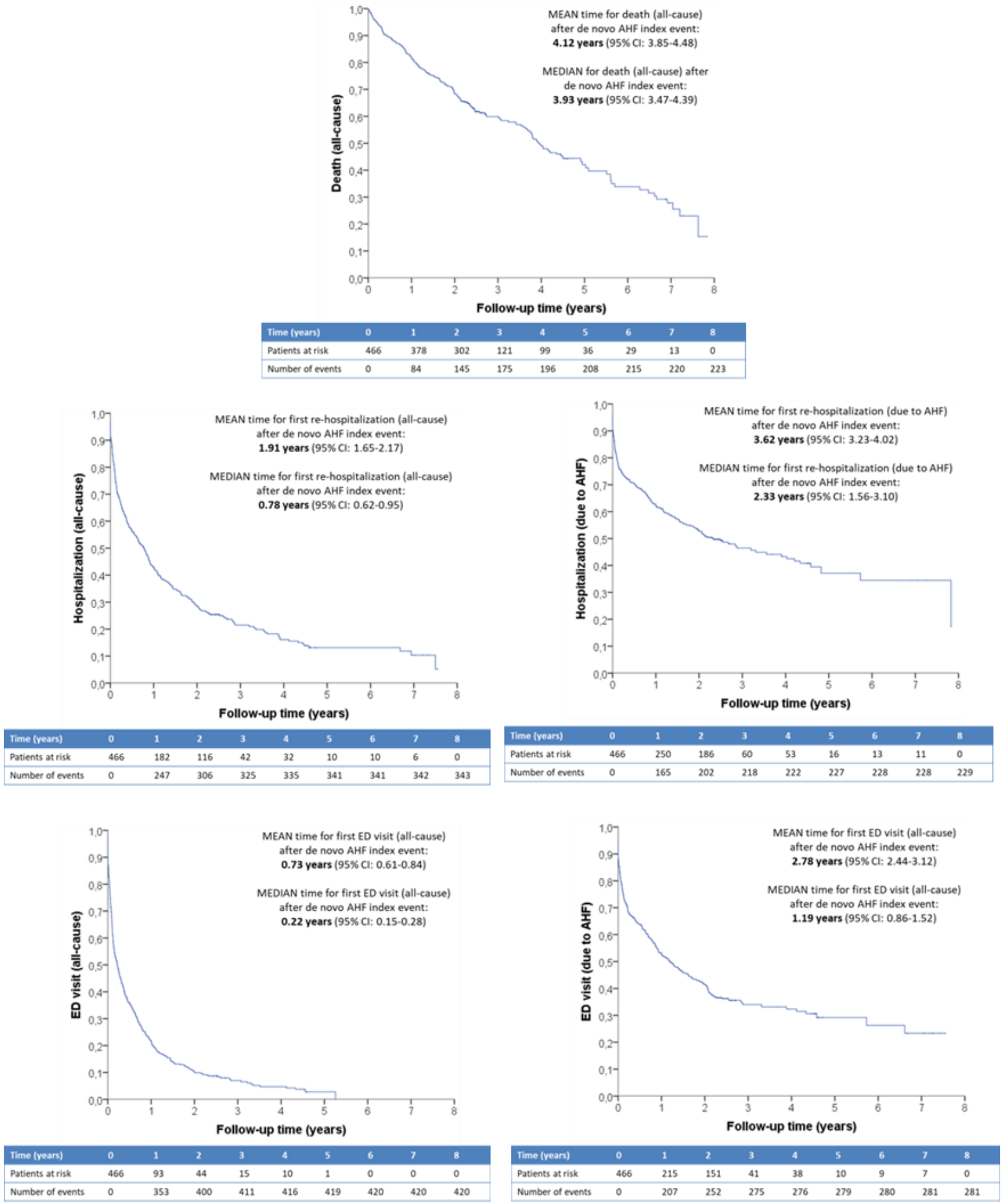
Figure 3: Location of hospitalization during index acute de novo heart failure (AHF) episode (left bar) and for subsequent re-hospitalizations.

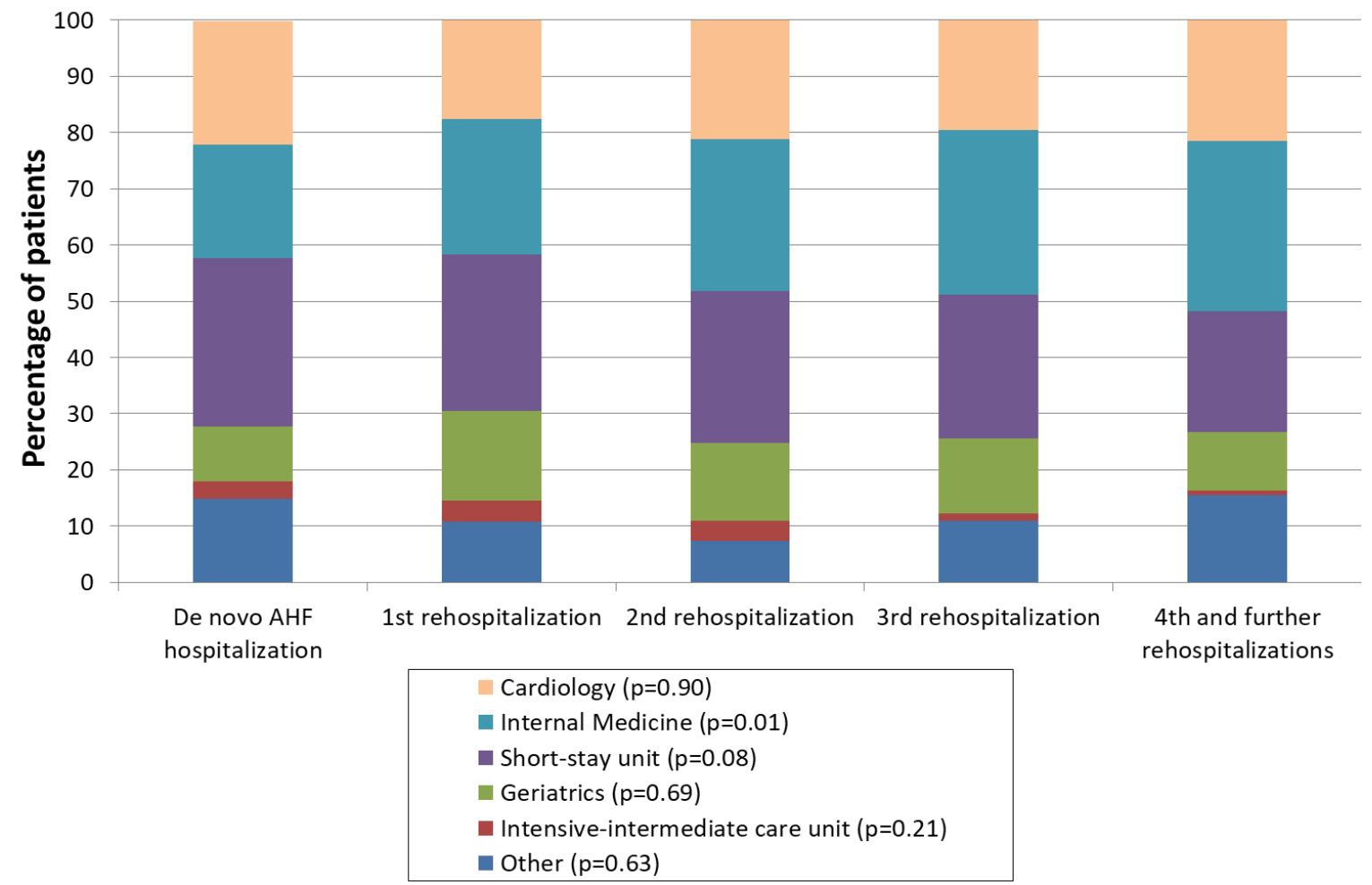

$P$ vaules were obtained through chi-square test for trend comparing the proportion patients hospitalized in each department as the number of hospitalizations increase in front of patients not hospitalized in such a department (i.e., hospitalized in the rest of departments). 
Figure 4: Relationship between the department responsible for the first hospital admission during the de novo acute heart failure (AHF) episode and the department where subsequent rehospitalizations took place, overall (upper pannel) and by the ordinal number of rehospitalizations (lower pannel).

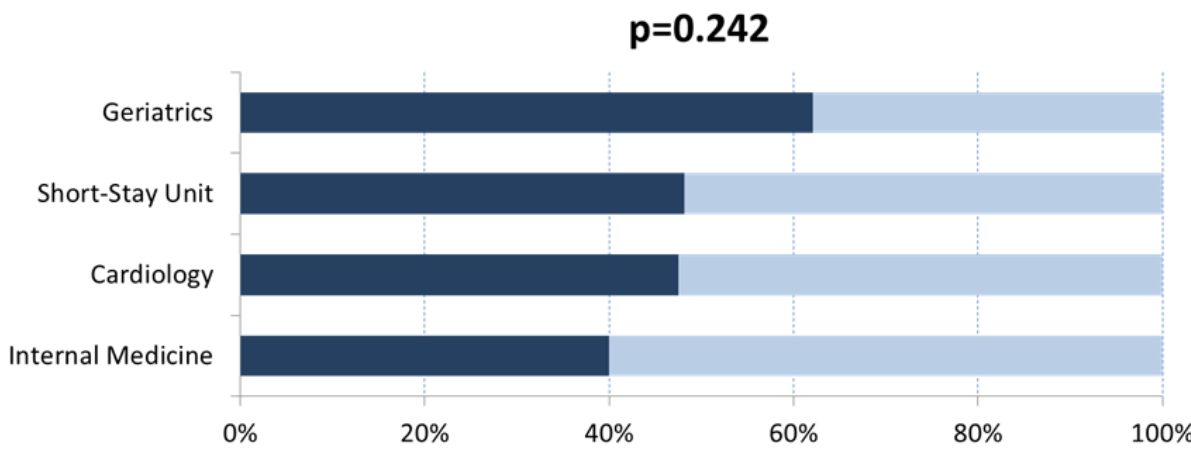

- Rehospitalizations performed in the SAME department that hospitalized the patient during the de novo AHF index episode

Rehospitalizations performed in a DIFFERENT department than department that hospitalized the patient during the de novo AHF episode

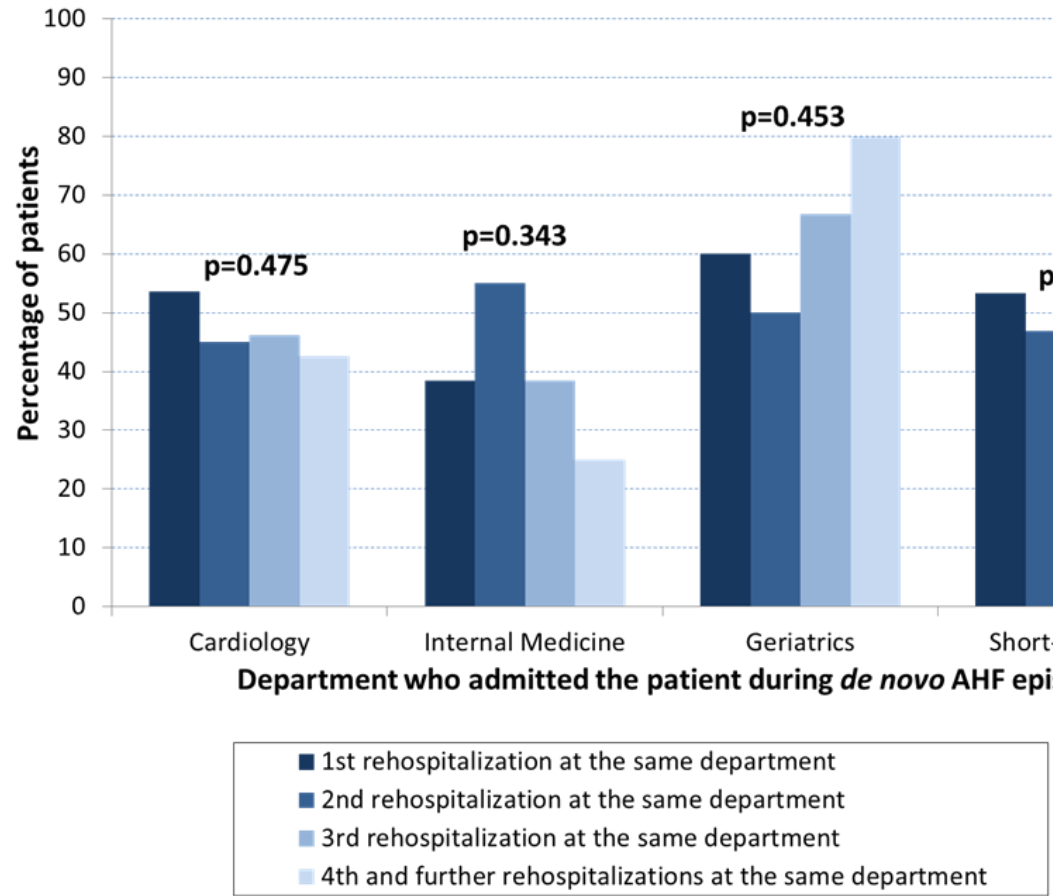

$P$ vaules were obtained through chi-square test (up) and chi-square test for trend (down) comparing the proportion of patients rehospitalized in the same department that hospitalized the patient during the first index episode of AHF in front of patients not hospitalized in such a department (i.e., hospitalized in the rest of departments). 
Supplemental Table 1: Dictionary of the variables included in the present study.

\begin{tabular}{|c|c|}
\hline \multicolumn{2}{|l|}{ DEMOGRAPHICS } \\
\hline Age & $\begin{array}{l}\text { Age calculated as the difference in decimal years between the date of inclusion in the study } \\
\text { and the date of birth. }\end{array}$ \\
\hline Sex & Male/Female \\
\hline \multicolumn{2}{|l|}{ MEDICAL HISTORY } \\
\hline Hypertension & $\begin{array}{l}\text { Indicate if the patient has arterial hypertension because this is shown under previoius clinical } \\
\text { history or the patient is receiving specific treatment. }\end{array}$ \\
\hline Diabetes Mellitus & $\begin{array}{l}\text { Indicate if the patient has diabetes mellitus because this is shown under previous clinical } \\
\text { history or the patient is receiving specific treatment. }\end{array}$ \\
\hline Ischaemic heart disease & $\begin{array}{l}\text { Indicate if the patient has any form of ischaemic heart disease (SCASEST, SCACEST, unstable } \\
\text { angina, stable angina, } \mathrm{ACl} \text {, etc) because this is shown under previous clinical history or the } \\
\text { patient is receiving specific treatment. }\end{array}$ \\
\hline Heart valve disease & $\begin{array}{l}\text { Indicate if the patient has any type of clnically significant heart valve disease according to an } \\
\text { ultrasound or haemodynamic study reported in the previous clinical history. }\end{array}$ \\
\hline Atrial fibrillation & $\begin{array}{l}\text { Indicate if the previous history describes permanent or chronic atrial fibrillation or an ECG } \\
\text { performed within the previous year shows atrial fibrillation and this continues to be present. }\end{array}$ \\
\hline Chronic kidney disease & $\begin{array}{l}\text { Indicate if the patient has chronic renal insufficiency or chronic kidney disease or if analyses } \\
\text { over the previous year show creatininevalues }>2 \mathrm{mg} / \mathrm{dL} \text {. }\end{array}$ \\
\hline Cerebrovascular disease & $\begin{array}{l}\text { Indicate if the patient has had a previous cerebrovascular accident or cerebrovascular disease } \\
\text { because this is described in the clinical history or shown in CT or MR imaging studies within } \\
\text { the previous year and reported as cerebrovascular disease. }\end{array}$ \\
\hline Peripheral artery disease & $\begin{array}{l}\text { Indicate if the patient has peripheral artery disease in either the lower extremities or carotid } \\
\text { artery, and if the patient is receiving specific treatment, has undergone specific surgery (by- } \\
\text { pass of lower extremities, endarterectomy, etc.) or there is previous history of an ankle } \\
\text { brachial index }<0.90 \text {. }\end{array}$ \\
\hline Dementia & Indicate if the patient has a previous clinical diagnosis of dementia performed by a doctor. \\
\hline Active neoplasia & Indicate if the patients has an active neoplasm \\
\hline Prior episode of heart failure & $\begin{array}{l}\text { Indicate if the patient has heart failure, is receiving specific treatment or the clinical history } \\
\text { reports previous episodes of AHF. }\end{array}$ \\
\hline \multicolumn{2}{|l|}{ BASELINE STATUS } \\
\hline Baseline Barthel index & Barthel index value of the patient at least 15 days prior to the date seen in the ED. \\
\hline $\begin{array}{l}\text { Baseline functional grade for dyspnoea } \\
\text { according to the NYHA scale }\end{array}$ & $\begin{array}{l}\text { Indicate the functional grade of basal dyspnoea (in the } 15 \text { days prior to the exacerbation } \\
\text { episode) of the patient according to the NYHA scale. }\end{array}$ \\
\hline Left ventricular ejection fraction & $\begin{array}{l}\text { Indicate left ventricular ejection fraction determined by echocardiography during admission of } \\
\text { current episode or, if not determined, the last one determined during the six previous months }\end{array}$ \\
\hline \multicolumn{2}{|l|}{ CHRONIC TREATMENT AT HOME } \\
\hline Diuretics & $\begin{array}{l}\text { Receiving chronic treatment with diuretics, either loop-diuretics, thiazide diuretics or } \\
\text { mineralocorticoid receptor antagonists }\end{array}$ \\
\hline $\begin{array}{l}\text { Angiotensin-converter enzyme (ACE) } \\
\text { inhibitors or angiotensin-II receptor blocker }\end{array}$ & Receiving chronic treatment with ACE inhibitors or angiotensin-II receptor blocker \\
\hline Beta-blocker & Receiving chronic treatment with beta-blocker \\
\hline Mineralocorticoid-receptor antagonists & Receiving chronic treatment with aldosterone-receptor antagonists \\
\hline Digoxin & Receiving chronic treatment with digoxin \\
\hline \multicolumn{2}{|c|}{ VITAL SIGNS AT EMERGENCY DEPARTMENT ARRIVAL } \\
\hline Systolic blood pressure & $\begin{array}{l}\text { Systolic blood pressure (SBP) measured in } \mathrm{mmHg} \text { of the patient on arrival to the ED. This value } \\
\text { can be that obtained during triage or the first taken on initiating care. }\end{array}$ \\
\hline Heart rate & $\begin{array}{l}\text { Central heart rate measured as beats per minute of the patient on arrival to the ED. V This } \\
\text { value can be that obtained during triage or the first taken on initiating care. }\end{array}$ \\
\hline Arterial oxygen saturation & $\begin{array}{l}\text { Oxygen saturation expressed as percentage obtained by capillary pulsioxymetry on arrival to } \\
\text { the ED. This value can be that obtained during triage or the first taken on initiating care. }\end{array}$ \\
\hline \multicolumn{2}{|c|}{ BLOOD TESTS AT EMERGENCY DEPARTMENT ARRIVAL } \\
\hline Glucose & In $\mathrm{mg} / \mathrm{dL}$ \\
\hline Creatinine & In $\mathrm{mg} / \mathrm{dL}$ \\
\hline Haemoglobin & $\ln \mathrm{g} / \mathrm{dL}$ \\
\hline Potassium & In $\mathrm{mmol} / \mathrm{L}$ \\
\hline Sodium & In $\mathrm{mmol} / \mathrm{L}$ \\
\hline Raised troponin & Indicate if troponin is above the 99th percent provided by the manufacturer \\
\hline NT-proBNP & In $\mathrm{pg} / \mathrm{mL}$ \\
\hline
\end{tabular}




\begin{tabular}{|l|l|}
\hline \multicolumn{2}{|l|}{ TRIGGERING FACTORS OF THE CURRENT EPISODE OF ACUTE HEART FAILURE } \\
\hline Infection & Active infection, of any system, considered to have a role in acute decompensation \\
\hline Rapid atrial fibrillation & Mean heart rate $>100 \mathrm{bpm}$, considered to have a role in acute decompensation \\
\hline Anaemia & Haemoglobin $<80 \mathrm{~g} / \mathrm{L}$, considered to have a role in acute decompensation \\
\hline Hypertensive emergency & Systolic blood pressure $>180 \mathrm{~mm} \mathrm{Hg}$, considered to have a role in acute decompensation \\
\hline Acute coronary syndrome & Symptoms starting before decompensation, and not developing after dyspnoea appearance \\
\hline Dietetic/Therapeutic transgression & High water or sodium intake, omission to take drugs prescribed for heart failure treatment \\
\hline Other & $\begin{array}{l}\text { Describe specifically other adjudicated causes of decompensation not included in the previous } \\
\text { episodes }\end{array}$ \\
\hline Multifactorial & $\begin{array}{l}\text { When some factors concur, but none is of sufficient magnitude to explain the } \\
\text { decompensation by itself }\end{array}$ \\
\hline None identified & When none of the previous factors can be selected \\
\hline
\end{tabular}

